\title{
Challenges of Organizational Ethnography: Reflecting on Methodological Insights
}

This has been published as: Daniel Neyland (2016) 'Challenges of Organizational Ethnography: reflecting on methodological insights' in F. Dykes and R. Flacking (eds) 'Ethnographic Research in Maternal and Child Health' (Routledge, London, pp. 179-198)

\section{Introduction}

It's 2 am on October $16^{\text {th }}, 2009$, and I find myself driving at speed toward the local hospital, my wife no longer able to convince me that she is not in labour. We are rushed through to a delivery suite and within a few hours our son is born. We are left by the midwives to spend some time with our new baby, but something is not right. My wife feels worse now than she did during childbirth. Is this what's supposed to happen? I go off in search of a midwife and she returns with a medical team. My wife is taken to theatre for a routine procedure. Meantime the baby is left to lie on me as I slump in an armchair. Having no young relatives, this is the first time I have ever held a baby. As she leaves, the midwife says: 'Try not to fall asleep.' I have been up all night, but I try to give her a look which communicates (without words): 'I am too scared to fall asleep.'

It's now $6 \mathrm{pm}$ on October $2^{\text {nd }}$, 2012, and this morning my wife was due to give birth by caesarean section to our second son. However, due to lack of staff our appointment was cancelled. Now (right in the middle of eating our fish and chips) my wife announces she is in labour. I find myself driving at speed toward the hospital once again. When we arrive, there are no staff at the reception desk. I leave my wife sat on a chair and try and find someone. I find no one. I return to find my wife on her hands and knees in the corridor. I return to the reception desk and find no one. I return to my wife, unsure what to do. I then spot a person in uniform (possibly a midwife?) and rush over to her. My wife is taken to theatre and our son is delivered.

Childbirth seems to effortlessly mix the normal and precarious, mundane and emotional. Sometimes short or prolonged moments of anxiety are combined with short or prolonged periods of happiness and these are combined with the banal exigencies of being processed through a mostly bureaucratic (in my case UK) healthcare setting. During research work I try and maintain as far as possible the following rule: 'If it's going well, enjoy it. If it's going badly, treat it ethnographically.' Up until now I have not had the chance to consider childbirth with such ethnographic scrutiny. However, having been invited by the editors to write some concluding remarks to this excellent collection, I now find myself in a position to do just that. What I will do, first, is try and draw together a brief history of organizational ethnography and highlight some of the implications that this history might have for working in healthcare settings. Second, I will try and set out some of the themes that I found most interesting and engaging from reading the chapters and focus on what seem to me the most pressing challenges in doing ethnographic work in maternal and child health settings. Third, I 
will conclude with what, for me, was a key insight of the chapters: a move from inter- or multi-disciplinary research to studying collective concerns. ${ }^{1}$

\section{A brief history of organizational ethnography}

In a general way, ethnography involves the observation of, and participation in, particular settings (such as local indigenous groups, management consultants, medical students and so on). This observation and participation aims to engage with questions of how a particular group operates, what it means to be a member of a particular group and how changes can affect that group. Although ethnography has been central to the development of various strands of scholarly thought, it has also always been entangled with practical matters. For example, the origins of ethnography in anthropology were closely tied to organizational endeavours - namely the management of Western European colonial engagements. Here anthropologists to some extent sought to bring the 'exotic' back 'home' (for an example, see Evans Pritchard's study of the Nuer, 1940) at the same time as offering a basis for colonial management. The entanglement of ethnography with an aim to manage and organise the settings under study has thus been of long standing.

Throughout the twentieth century these ethnographic origins were taken in many directions through anthropology (for an augmentation of the 'exotic' through thick description, see Geertz, 1973), sociology (from the study of slums, see Whyte, 1955, through to youth culture, see Cohen, 1970), science and technology studies (see, for example, Latour and Woolgar, 1979) and the development of new avenues of exploration. Hence in the twenty-first century discussion of ethnography has found focus in considerations of the understanding and use of technology (see Miller and Slater on Trinidadian's use of the internet, 2000) and in questions of ethnography's ability to engage with messy, complex and chaotic organizational forms (Law, 2004) among many other areas.

These developments have continued ethnographic engagements with organizational settings. Anthropology continued to be closely involved in western colonial activities in the first half of the twentieth century. Indeed this involvement was crucial to the development of ethnography as a research method. For example, the early pioneering work of Malinowski (1929) and Radcliffe-Brown (1922) has been identified by many (see, for example, Burgess, 1984) as providing the basis for the development of ethnographic fieldwork. Prior to these studies, many ethnographers had simply collected second hand accounts of exotic lands from travellers returning to, for example, Britain (Urry, 1984) or had been involved in the development of questionnaire type approaches to map out practices of colonial groups (Ellen, 1984). Malinowski advocated direct participation in the groups being studied and advocated using such participation as the central focus for developing an understanding of the group. The ethnographic principles of getting close to the group and spending a great deal of time in the group emerged at this time.

Baba (2005) suggests that the popular view that this colonial entanglement provides something of a blot on the history of ethnography, is a relatively recent reading of events and that early anthropology involved both practical and scholarly pursuits. She argues that "In the

\footnotetext{
${ }^{1}$ I have borrowed this term from an event organised by Christian Frankel, José Ossandón and Trine Pallesen. 'Markets for Collective Concern?' Copenhagen Business School, $11^{\text {th }}$ and $12^{\text {th }}$ of December, 2015.
} 
past, relationships between pragmatic and scholarly interests were fuzzier and more entangled than the received version would have us believe," (2005: 206). Drawing on the work of Kuper (1983) she points out that forms of applied anthropology date from at least 1881 "when British anthropologists used it to advocate the potential utility of their emerging profession which did not yet have a firm constituency," (2005: 206). Early ethnography combined practical and scholarly pursuits, but not in seamless ways. Often practical work (depending on funding and availability) was handed over to junior colleagues (often women) beginning a separation between (more esteemed) theory and (lower status) practice.

Histories of ethnography (such as Baba, 2005) suggest that the funding for such theoreticalpractical work continued through the Second World War in line with endeavours to engage with colonial groups. Post-independence and the end of empire, such interest dwindled. Schwartzman (1993) argues that simultaneous to the decline in colonial, practical studies, anthropology moved into new and distinct settings raising new practical questions for ethnography. The Hawthorne studies of the 1920's and 1930's involved ethnography moving in to the workplace. Schwartzman highlights how Lloyd Warner suggested "work groups could be studied as a type of small society," (1993: 9). Although these studies were subsequently criticised for apparently representing the workers as less logical than their superiors, this research began to indicate that anthropological techniques, spending time in the setting, producing a detailed picture of the mundane and the ordinary, could have potential for studies 'at home' as much as in 'exotic' locations abroad. The practical approach taken by these ethnographers was emphasised by Lloyd Warner who went on to found a consulting firm, Social Research, Inc.

In recent years there has been something of a reinvigoration of questions of ethnographic utility for organizational settings. The Xerox Paolo-Alto Research Centre (PARC) employment of ethnographers has renewed questions of ethnographic research and the possibility of combining scholarly ethnographic research with practical and pragmatic considerations. Suchman (2000) has even asked if anthropology itself has now become a brand. But anthropology has not had an exclusive hold on the use of ethnography for social science research. While anthropology began through ethnographic engagements with 'exotic' tribes in far-flung places, sociological ethnography began with subject matter closer to home. These sociological beginnings also drew together ethnography as a scholarly pursuit with practical and pragmatic (in this case, political) questions. The Chicago School (for a discussion, see Fielding, 2001) used ethnography for the practical political purpose of enhancing knowledge of particular groups within inner-city slums who, they claimed, were poorly represented by statistical analyses which offered little information on who people were, what they did, how they organized their lives and what problems they faced. Ethnography was deployed here in order to get close to those who dwelt in the poorer areas of cities in order to make available insights into their lives which might provide some political leverage. The explicit political aim of the likes of Whyte (1955) and his study of the street corner life of Boston slums, was one of adequate representation.

These studies were not designed to make available the obvious, or 'things we all know about' the particular group under study. Instead these studies made available detailed, insightful and often counter-intuitive pictures of, amongst other things, the complex organization of marijuana users (Becker, 1973) and fighting between rival gangs (Cohen, 1970). This counter-intuitive aspect of ethnographic research has been important in making available 
detailed analysis of the activities of particular groups which had been absent from media and legislative discourse.

A third and more recent focus for ethnographic development has been the field of management research. Sporadic calls have been made for the relevance of ethnography for addressing quite traditional concerns within organizational and management research. In for example, organizational behaviour (Bergman, 2003), strategy (Whittington, 2004) and accounting research (Dey, 2002), forms of ethnographic research have been utilised in order to address questions of 'culture,' 'strategic practice' and 'change.' However, the separation between management research and anthropology is not clear cut (see for example, Darrah, 1996; Rosen, 2000). Baba (1986) suggests that the origins of organizational behaviour lie in anthropological research such as the Hawthorne studies. It was in these studies that the grounds for in-depth, up-close studies of the everyday, routinized, informal activities of the workplace were established.

Czarniawska-Joerges (1992) traces the historical shifts which saw the fields of anthropology and management research move apart over time. She suggests that organizationalmanagement research developed rapidly in the 1950's and 60's, moving away from anthropological ideas towards supposedly scientific notions being developed in much sociological research at the time (for example, sociological researchers were pushing the development of survey sampling techniques, statistical formulas, experimental designs and data processing). However, Bate (1997) argues that it may be time for reconciliation. Bate identifies moves being made in the UK and more prominently in the US to bring together anthropological and organizational behaviour concerns, highlighting the importance of getting close to subjects under study, making available routine aspects of organizational activity for analysis and studying 'history' and 'context.' Furthermore, although management and anthropological research has been separated in the past by anthropologists' study of the exotic and management researchers' focus on organisations 'at home' (Burack, 2002), this is no longer such a clear distinction with many anthropologists also studying the exotic at home.

In line with sociological ethnographies which sought to question 'what we all know about' particular groups through, for example, media reportage, Bate (1997) suggests that organizational ethnography has an important part to play in management research by demonstrating counter intuitive aspects of organizational activity. Bate draws on examples such as Latour and Woolgar's (1979) study of laboratory scientists which suggested that objective, factual scientific method is far more complex and far less clear cut than may be taken for granted. It is such counter-intuitive results, Bates argues, that offers ethnographic researchers the possibility of producing revelatory findings. Getting close to the organizational action is not just about telling the audience what they already know but also involves a refusal to take anything for granted. In the same way that anthropologists encountered exotic locations, tribes and customs, the organizational ethnographer can shift the everyday into the exotic, by carrying out detailed and close examination of their subject matter. In the same way that Chicago School sociologists made available rich and textured detail of life in the ghetto which (counter to media reporting at the time) demonstrated the level of organization of street corner life, organizational ethnographers have the opportunity to scrutinise even the most apparently banal features of organizational activity to analyse what they suggest about the characteristics of the organization under study. For example, Weeks (2004) provides a detailed ethnographic analysis of organizational complaining, at 
once both an ignored and frequent feature of workplace settings. Through a thoroughly sceptical treatment of each aspect of organizational activity the ethnographer can get close to those everyday features of activity which hold the organization together. Van Maanen (1979) argues that the purpose of organizational ethnography is "to uncover and explicate the ways in which people in particular work settings come to understand, account for, take action, and otherwise manage their day-to-day situation," (1979: 540).

This brief history of ethnography has suggested that ethnography in anthropology, sociology and management research has from its very beginnings involved a practical and pragmatic element, exploring the bases for organizational engagement. What might this mean for healthcare settings? In anthropological research we find attention paid to the continuing entanglement of doing ethnography and (attempts at) being useful. Pigg (2013) for example suggests that anthropological ethnographers continue to be pressurised to focus their research in ways that provide useful outputs for the organization under study, advocating instead: "a practice of patient ethnographic 'sitting' as a means of understanding, as a form of critical reflexivity, and as a diagnostic of the politics of relevance," (2013: 127). Other ethnographic work in healthcare settings continues to push the counter intuitive insights of ethnographic work by, for example, examining the complex ontological choreography of healthcare settings (Cussins, 1992), the ontological multiplicity of particular conditions (Mol, 2002) or the ways in which apparent healthcare futures establish accountable expectations for healthcare professionals in the here and now (Neyland and Coopmans, 2014). Being useful as an ethnographer in healthcare settings appears to continue many of the same themes I have briefly illustrated in the preceding history of ethnography; attempting to figure out a way to be useful for scholarly or more practical and pragmatic audiences; or figuring out a way of managing relations with 'audiences' who are not straightforwardly external to the research (but may in fact be participants in the research).

These kinds of issues should not come as a surprise. I have previously suggested (Neyland, 2008) that ethnographic research comes with a number of significant challenges. How to manage field relations with research subjects along with broader relations with the organization under study, the collection and analysis of data, timing, entry and exit from the field, questions of knowledge, ethics, research design and execution, seem as resonant in healthcare settings as they are anywhere else. What I found engaging across this collection was the number of different ways in which these challenges could be taken up, reported on and navigated. In the next section I will try and provide an account of what I thought were the main and most compelling themes of the chapters and the challenges they posed for doing ethnography in maternal and child health settings.

\section{Chapters and Challenges}

I enjoyed the array of viewpoints and approaches organised among the chapters to this collection. I noted a number of challenges that were common across several chapters that were each approached differently by different sets of authors. I have arranged these challenges under five sub-headings here, but these chapters were sufficiently rich that they could have been re-arranged in a number of different ways. 


\section{Knowledge and ways of knowing:}

There has been a long-standing interest in ethnography with questions of knowledge and ways of knowing. These questions relate to both the forms of claim to knowledge made by ethnographers and the ethnographic study of knowledge practices within various settings (see for example Knorr Cetina, 1999). Ethnographic ways of knowing have typically (Neyland, 2008) been divided into, for example, forms of realist, narrative and reflexive ethnography. These each depict a different basis for knowing the world. Epistemologically they divide the world into different relations between, for example, the knowing subject and the known, and ontologically they treat the relation between the ethnographic text and the nature of the world in distinct ways. Hence realist ethnographies (see for example Radcliffe Brown, 1922) tend to assume that the activities being observed exist independent of the study and could be gathered together as a more or less definitive representation of the group being studied. Realist approaches to knowledge are in many ways the most straightforward for questions of observation and representation. What is seen is taken (more or less) as a definitive version of what is going on. Narrative ethnographies (for example, Whyte, 1955) are often based around a notable informant whose views of 'what is going on' are taken as a valuable (but not the only possible) version of events. These narrative accounts of the field are often utilised to get close to a group who may not be easily accessed (for a discussion of alternative ethnographic styles, see van Maanen, 1988). The ethnographic account thus becomes one way of knowing among others without assuming that the nature of the world is itself easily accessible. Instead, more radical reflexive ethnographers suggest that the ethnographic 'reality' being studied is not independent of the ethnographers' work to produce an ethnographic text. Reflexive ethnography makes no claims for objectivity or knowledge neutrality, but rather seeks to emphasise its validity through reflexive subjectivity. The ethnographic text thus might constitute one (but not the only available) nature of the world.

It seems to me that these questions of knowledge and ways of knowing the world can become particularly clear when engaging with organizations. Organizational ways of knowing seem to stand in contrast to ethnographic ways of knowing on a regular basis. However, what the chapters in this book suggest is that although the aforementioned three part list of ways of knowing (realist, narrative and reflexive) can provide a useful heuristic for engaging with knowing, the ethnographic practices of knowing, even in a broadly shared focus such as maternal and child health settings, can be varied and require consideration on their own terms. For example, Gammeltoft's approach suggested that collective ethnography involved different ways of producing knowledge and different combinations of knowing ethnographers (with insiders and outsiders to the community incorporated into the research team). In this way an ethnographic text moved beyond a single mode of knowing to a collective effort. As a contrast, O'Boyle looked toward auto-ethnography as a basis for exploring professionalism. What got to count as adequate knowledge was a form of reflexivity, but one that might not just involve looking at oneself, but might involve encouraging others within the profession to reflect on their actions. In place of a potentially problematic distinction between an ethnographic and organizational way of knowing, the distinction became a point for practical reflection. In a similar vein, Flacking and Dykes utilised reflexivity as a basis for exploring the ways in which the different backgrounds of each author constituted a distinct sense of the settings in which they researched. 
Collective and auto-ethnography were not the only ways of knowing considered by the chapters. For Schmied, Burns and Dahlen, theory provided a means to frame their ways of knowing the field. Drawing on the work of Foucault provided a means to rework the ethnographic data and organizational implications of their study. However, alongside such theoretical concerns, the ordinary and mundane features of organizational activity also seemed to play a role in shaping ways of knowing. For Hugill, even the type of clothing worn in the setting altered the experience of doing research, the types of data collected and the expectations among other members of the research setting, including the research participants. Ways of knowing, for Hugill, were also re-oriented by familiarity with the settings in which the author had previously worked. When Young and Pelto described ethnography as a basis for supporting evaluation, it seems clear that as a way of knowing this stands quite distinct from conventional academic ethnographic relations of knowing. What I found most insightful about this range of approaches to questions of knowledge was that, as an outsider to maternal and child health, they applied to different (multiple settings, countries, procedures and practices) and the same thing (maternal and child health).

\section{Field relations and the handling of data:}

Closely related to the challenge of how to engage with knowledge and ways of knowing are questions related to the management of field relations and the data such relations produce. The time an ethnographer spends in the field almost inevitably means that they will strike up closer relations with research participants than, for example, a distant survey or even a brief interview. This close relationship is important for gaining in-depth, up-close views on what it is like to be a member of a particular group or organization. By participant observing the ethnographer becomes an effective member of the group. This membership can be illuminating for ethnographic research providing insights into what status membership confers, how individuals shift from being non-members to members and what it means to cease membership. However, managing such relations can also be challenging. Ethnographers can establish rapport with one or a few key informants who provide much of the observational data for the research (Whyte, 1955), and can establish relations with gatekeepers who introduce the ethnographer and aid the ethnographer's move from location to location (Geertz, 1973). At the same time, the centrality of these figures to the data produced requires consideration. Furthermore, close field relations also engender relations of trust. Trust can be thought of as those close relations established between ethnographer and research subjects which lead to the mutual exchange of relevant information. Trust relations can involve work on the part of the ethnographer to establish that the research being carried out is rigorous, relevant and/or has some utility.

What I found in the chapters to this collection was a number of distinct ways in which authors positioned themselves among organizational members or managed such relations at a distance. These relations seemed to have direct consequences for the types of data collected and thus the study of the organisation that resulted. For example, Brimdyr's study was informed by ethnomethodology and the orientation to get close to members methods for making sense of the organizational setting. At the same time, and in line with other ethnomethodological studies of workplace activities, Brimdyr used video recordings as the basis for study. This research at a distance established a very particular basis for doing the 
research; that the members' methods for making sense of the setting could be studied through video and the ethnomethodologist's insights would not directly or immediately participate in those members' methods. Similarly, Taylor, Tully and Ball used video recordings as a basis for bringing data to attention.

Alternative approaches to field relations had different consequences for data collection and handling. For example, Gammeltoft approached the study from an anthropological approach, but also steered readers toward innovation through collective engagement with the field. Field relations thus multiplied. O'Boyle's auto-ethnography was as much informed by a professional history as it was an opportunity to reflect on it, while also being infused with ideas of narrative as providing the basis for an informed and rigorous account of the field. In this way, the author's own history became an integral feature of field relations and the data it enabled. For some authors, field relations were not stable. In this way, although Hugill intended to carry out an observational study as a basis for collecting data, participation continued to be an inevitable feature of being in the setting.

However, 'field relations' could also become focused on the close management of organizational interactions, in that for Flacking and Dykes, for example, small rooms provided a difficult space in which to approach research (their presence in a small room seemed more like an assessment of research subjects) whereas larger spaces proved to be easier locations for navigating their research work and the sensitivities of participants. In a similar manner, Taylor, Tully and Ball looked to minimise the awkwardness of researcher presence by video recording night time activity on the postnatal ward as a basis for removing the ethnographer from the setting. Field relations, the field site and the outcomes of the research were inseparable.

This diversity among field relations and types of data, also continued into the handling of ethnographic data. Gammeltoft approached research accounts as matters to be treated with caution, providing opportunities to explore what was said in an account and what was partial or absented. Schmied, Burns and Dahlen explored the advantages of drawing together data by synthesising multiple studies that they had completed. And in a similar manner, Flacking and Dykes argued for a comparative analysis across countries and settings and organizational scales. What I noted in the chapters was the rich array of insights achievable from following these field relation and data struggles between chapters; that what counts as good data or successful relationships in the field are never settled within a study, but can be usefully compared across studies.

\section{Ethics:}

A third area that was noted among some authors was the issue of ethnographic ethics. Ethics have been a complex area for organizational ethnographers to navigate. From an academic perspective, ethnographers have tended to establish what the ethical requirements are in relation to their own academic institution and through local and national guidance. Historically, there have been three main approaches to ethics: ethics as rules which attempt to define in a relatively rigid manner the ethical direction of the research; ethics as guidelines which attempt to provide general principles which researchers should make relevant for each piece of research; and ethics as accomplishments through which researchers produce ethical 
outlines tailored to the setting for corroboration by academic peers, research funders and ethics committees. An alternative focus for ethical clearance has been the organizations under study. Access negotiations in relation to an organization can involve discussions of ethics, may require the ethnographer to demonstrate knowledge of the organization's ethical guidance, or alternatively the organization may wish to enter into a pre-research agreement on ethics. Such negotiations can be insightful in revealing concerns characteristic of particular organisations.

Despite the health-related subject matter of the chapters in this collection, ethics on the whole did not seem to have been treated as a significant challenge. Perhaps this is because doing research in healthcare settings comes with certain prefigured expectations and processes as to how ethics will be managed. Rather than act as a challenge to research, ethics becomes more like a standardised process. In the chapters, though, there was some diversity among the brief discussions of ethics which suggests a single standard for ethically conducting research did not dominate studies. For example, Brimdyr suggested a formal approach to ethics with clear agreements in place, whereas O'Doyle approached ethics as a matter of anticipatory selfregulation, attuned to the demands of auto-ethnography and Flacking and Dykes suggested that ethical considerations resonated differently for the different national settings of their research. This suggests that ethics continue to be a challenge for the local management of ethnographic studies.

\section{Findings:}

A fourth challenge that seems central to doing ethnographic work is the production of findings. This is challenging in a number of ways. First, there is the challenge of, in some instances, understanding and meeting the expectations of organizations in which the research is being carried out (I will say something more on being useful under the next sub-heading). Second, there can be a compression of time in organizational ethnography from thick description to quick description (Bate, 1997). Geertz (1973) developed the term thick description to describe a style of ethnography with rich story-telling of incidents in the field providing the backdrop for a developing understanding of the setting. To move to quick description suggests that the space between the initiation of research, its completion and the production of findings is compressed. This seems to threaten some of the principles of ethnographic research - that the researcher gets close to the members of the organization being studied, that time spent in the field enables the researcher to produce a detailed and indepth picture of what is going on in the organization and that the findings emerge from the ethnographer's movement back and forth between previous observations and constantly emerging new observational materials (see Hammersley and Atkinson, 1995; Fetterman, 1989). Third, I mentioned in the brief history of ethnographic engagements which opened this chapter, that a long standing quality of ethnographic research is to show something different, to not tell us what we already know about a setting, but to provoke and challenge our conventional ways of thinking. In producing organizational ethnographic findings, this poses the question: What can be said (and to whom) that retains the opportunity and ability to provoke?

Despite these apparent challenges involved in organizational ethnography, I found a number of ways in which authors had found ways to produce findings which upheld and extended the 
strengths of ethnographic research and even managed to provoke me to think in different ways. For example, O'Doyle produced findings both insightful and provocative. O'Doyle emphasised that what was important was the relation between a context of legislation and policy, and the actions of individuals (in particular midwives) who had to make decisions on professional standards and forms of care and the maintenance of their own professional status. O'Doyle's own struggles with this continual movement between the policies and everyday practices and necessities of healthcare settings opened for me an opportunity to experience in detail the difficulties and consequences of those movements. I found this combination of relevant, but also provocative, findings quite apparent across the chapters. Hence, Gammeltoft suggested that decision making in regard to, for example, termination was a matter of attachment and detachment; intersecting theory with practice. Gammeltoft's distinction between heroic individual ethnographers and less heroic collectives could also act as a methodological provocation for ethnographers.

Other chapters looked to provoke in different ways. For example, Brimdyr suggested that moving others' expectations away from generalizable findings toward the importance of context specific studies might be a challenge. In some senses, arguing for context specificity might still prove a provocation for some. Schmied, Burns and Dahlen looked to Foucauldian notions of disciplinary power as a basis for questioning existing practices within maternity and child health care settings. In this way, the midwife was positioned as the expert in procedures and reporting but also in self-monitoring; internalizing the disciplinary gaze of the healthcare bureaucracy to such an extent that meeting targets might start to outweigh the needs of women in maternity settings. For Flacking and Dykes, being non-local provided a basis to treat everything as strange. In this way, being a non-native English speaker became an advantage in the UK part of their research as it continually prompted the question: what are these people talking about? And perhaps the basis for engagement (see next section) can itself be a provocation with, for example, Young and Pelto shifting the traditional academic virtues of ethnographic engagement toward impact evaluation. What I found across the chapters was not so much that the challenge of producing findings within organizational settings limited provocations or ways of doing research. Instead the organizational settings appeared to form the basis for innovation. I will explore this further in the next section.

\section{Engagement with the organization:}

I noted in the opening to this chapter that ethnographers had on-going engagements with scholarly and practical activity. For example, from the initial development of ethnography in anthropological studies of colonial settings, we can also find the early development of ethnography for colonial management (Baba, 2005). Although some have suggested a division between scholarly and practical pursuits since its early development (Baba, 2005), ethnography continues to be engaged with forms of design (Hughes et al, 1992), marketing (de Waal Malefyt and Moeran, 2003) and organizational review (Schwartzman, 1993). While this ethnographic activity might, as Moeran (2005) suggests, mostly adhere to its origins in practising "long-term involvement with and study of the everyday lives, thoughts and practices of a particular collectivity of people," (2005:3) it has also on occasions become "a buzzword that covers virtually every kind of data collection available to market researchers, from telephone surveys to focus groups... [and] interviews," (2005:11). What we can note, 
then, is that ethnography in organizational settings both offers opportunities for innovation, but in innovating it also risks losing its methodological distinctiveness. However, we can also note a further challenge. Despite being provocative, and challenging audiences to think in different ways, and despite being innovative in method, it remains that ethnographies within organizational settings are often not just designed as a study of a setting but are expected to produce findings for that setting. Managing the challenge of on-going methodological innovation must on occasions sit alongside managing the challenge of saying something of use.

These twin challenges have been taken on in different ways by different authors. For some, an important feature of organizational ethnographic research, is the progressive identification and accumulation, in the process of the research, of connections with participants and other potential 'users.' However, in line with explorations of "interactive social science" (Woolgar, 2000; Caswill and Shove, 2000) and engagement in research programmes incorporating novel forms of outreach (Woolgar, 2002a; 2002c), it seems that user relations cannot be taken for granted. The reflexivity which often forms a feature of the production of ethnography (Atkinson, 1990; 1992) can be extended here to considerations such as how and to what extent the researchers are themselves accountable for the value and utility of their research (Woolgar, 1998; 2002b; Neyland 2006). Careful consideration is required of the precise implications of utility in relation to organizational ethnography.

Assessments of utility form one feature of moves made to inaugurate a shift towards the marketability or customer orientation of research. As Du Gay and Salaman (1992) argue, there is hardly a public service organization in Britain "that has not in some way become permeated by the language of enterprise," (1992:622). This language of enterprise, however, is not a "vague, incalculable 'spirit,' the culture of enterprise is inscribed into a variety of mechanisms, such as application forms, recruitment 'auditions,' and communication groups," (1992:626). For Rappert (1997) one such mechanism can be found in University funding bodies' establishment of particular themes. These themes call for the "incorporation of users' needs," (1997:1) and suggest that "customer-contractor relations" (1997:2) are an important basis for research funding. This is ever more apparent in the UK with funders such as the ESRC expecting statements on the proposed 'impact' of research at the point when funding is applied for (rather than in a final project review) and 'impact' cases being made central to the Research Excellence Framework. These moves are positioned under broader motifs such as the "need to meet the challenges of international competitiveness and improve the quality of life," (Rappert, 1997:1). Gibbons (2000) ties this shift in research funding to the shift he identifies from Mode One to Mode Two research activity. Rather than setting research problems and solving them (Mode One), science and social science research is now more closely incorporated into the context of application for research and is produced via teams of mixed-skill researchers in close collaboration with users (Mode Two). In this sense organizational ethnography could be understood as shifting from study of the organization to combinations of study of and for the organization.

However, several social scientists (for example, Woolgar, 2000; Shove and Rip, 2000) warn against assumptions regarding the ease or comfort of interacting with practitioner audiences. Shove and Rip (2000) suggest "the over-reliance on an embodied notion of use and uncritical acceptance of associated pathways of influence is understandable but unnecessary... In short, the challenge is to understand better the process of use even if that means abandoning the 
comforting fairy-tale of the research user," (2000:175). This aligns with Woolgar's (2000) suggestion that "we should accept that users' needs rarely pre-exist the efforts and activities of producers to engage with them," (2000:169). These arguments contribute to a social science history of the difficulties of user interaction. For example, caution is advocated as to the "circumstances under which social science research enters the decision-making domain," (Weiss and Bucuvalas, 1980:248), with suggestions made that social science findings are prone to be misinterpreted, misunderstood or misused. Furthermore it is argued that social science is often "underutilised" (Wagner, Weiss, Wittrock and Wollman 1991:5), with findings on policy principles not used to their full extent. Warnings are also given against any assumptions that good social science will automatically be utilised. Thus Heller (1986) suggests that: "while only a few people would argue specifically against making use of existing social science knowledge, it should not be assumed too readily that a broad-based advocacy of more utilisation is either logical or practical," (1986:1).

The challenges posed to organizational ethnography in attempting to demonstrate its utility cut to the centre of the methodology employed. Concerns with, for example, ethnographic timescale and its mismatch with claims regarding the necessity of organizational speed (see, for example, Jeffrey and Troman, 2004) and organizational sensitivities regarding the provision of access for long periods to particular areas of organizational activity (see, for example, Harrington, 2003) are frequently cited as problematic features of ethnography's attempts at addressing practitioner audiences.

Despite these challenges, I noted in the chapters a number of ways of attempting to communicate useful insights and forms of ethnographic utility to organizations involved in the studies. For example, Brimdyr's study emphasised the importance of the first hour of a baby's life and the contact that it established between mother and baby. Further, Schmied, Burns and Dahlen suggested there might be an innovation gap in failing to bridge best practice between settings. Although these studies do not perhaps resolve all the preceding discussions of use and utility, they do point toward findings that organizations could seek to employ. Similarly, Flacking and Dykes suggest that their comparative study provided different findings in different locations, but also some common themes. For example, breastfeeding was a relational activity not a target to aim toward. And Taylor, Tully and Ball suggest that their study of night time on the postnatal ward suggests a need for maternal support. Finally, Hugill argues that although the stress of preterm births for parents is acknowledged, the specific experiences of fathers requires closer attention.

This suggests a broad number of different insights of potential practical import. However, I suspect a number of the questions from the preceding discussion of utility still pertain. It might be that distinct expectations between organisations and researchers remain (Jeffrey and Troman, 2004), that a willingness to allow ethnographic research perhaps sets up particular expectations (Harrington, 2003), that users, use and usefulness do not straightforwardly precede research, but are entangled in the production of research (Woolgar, 2000; Shove and Rip, 2000), that without careful management research could be mis-used (Weiss and Bucuvalas, 1980) or under-utilised (Wagner, Weiss, Wittrock and Wollman 1991). Yet the chapters seem to tell a different story. This was not a story that denied these issues, but instead looked towards methodological innovation as a basis for exploring utility. 
In this way, Brimdyr produced a study which was mostly designed to be productive for the organization studied; working through video as a basis for producing insights and following a model to provide steps toward sustainable change. O'Doyle implied that through autoethnography, the professional practice of the researcher and the tasks of completing research could be drawn together. Taylor, Tully and Ball produced findings that were based on a study of the organization that might have useful implications for the organization, for example in suggesting that on occasions there might be insufficient staff on night time post natal wards. Young and Pelto suggested using a form of ethnography as a basis for impact evaluation and as a basis for supporting other methods of data collection such as surveys. The need for innovation, seemed to me to indicate both the difficulties of doing organizational ethnography and the possibilities on offer.

\section{On Collective Concerns}

In conclusion, in place of drawing together the chapters and their rich insights (which have already been covered by the preceding description), I want to look at the idea of a collection in a bit more detail. What I have noticed, coming to maternal and child health as a relative outsider, is that the collection itself (rather than any particular chapter or individual insight) is of the greatest importance. It is the collection through which the value of the chapters is accomplished. In particular, the collection is where the challenges of disciplines and utility come together and are to an extent resolved.

I will say a few words first about disciplines before going on to say something about utility and why the collection offers a way forward. Drawing together a diverse collection of chapters such as those that precede this text, runs various kinds of risks. Different methods, different theories, different aims, different outcomes pose risks. These risks can be grouped together under the broad umbrella term of inter-, trans-, multi- or post-disciplinary research. I work in an area (Science and Technology Studies) which is often considered to be interdisciplinary, trans-disciplinary, multi-disciplinary or post-disciplinary. Like many others I come into contact with these risks on a regular basis. Much of my consideration of discipline and its risks feature in funding applications where I am explicitly called upon to demonstrate evidence of the breadth of conventional disciplines which will be incorporated into the promised research. Although I tend to use stock phrases in research proposals to demonstrate interdisciplinary activity, I have never greatly understood why I am called upon to do so or how these stock phrases might establish future commitments on which I will be assessed. Indeed I believe the stock phrases originate from a funding application written by a colleague (and perhaps he borrowed them from previous applications?). What remains clear is the expectation that the applications should be able to demonstrate this sought-after commodity. Although one could devote a research project to tracing the history of these interdisciplinary expectations in research proposals, that is beyond my scope here. Instead I would like to briefly explore four risks involved in doing interdisciplinary work and the general problem of assuming interdisciplinary research is inevitably an improvement upon disciplinary research.

First, interdisciplinary research often involves one approach simply taking on questions which have traditionally been the focus of another discipline. This involves a form of 
empirical imperialism. A problem with this approach is that the imperialist usually claims that they will address questions the original approach has found intractable by bringing in wonderful new insights from their own field - ignoring the possibility that the questions are likely to be as intractable, even given the fresh perspective, or ignoring the possibility that multiple disciplinary perspectives multiply problems.

Second, interdisciplinary research can involve one approach adopting the methods of another approach - a form of methodological imperialism. This often involves the imperialist attempting to export the method as a technique, leaving behind a great deal of methodological baggage. The result is the baggage is simply delayed in its arrival and generates problems at a later date.

Third, interdisciplinary research takes on the theoretical approaches of another area in order to address some of its own long-standing questions - a kind of epistemological imperialism. A frequent problem here is that the version of theory which gets carried across is hopelessly watered down in order to make it more palatable to the new audience.

Fourth, the notion of discipline for many scholars (e.g. Foucault) is tied into notions of punishment. For all the talk of inter/trans/post-disciplinary work, I still have the sense that inappropriate disciplinary transgressions are likely to be academically punished by peers who consider inter/trans/post- work to be irrelevant to them (as it is 'outside' their discipline) or, worse, an impoverished version of acceptable work within the discipline.

I have the general suspicion that I have, at times, been guilty of all these forms of imperialism and attempted to gloss over problems with discipline. Perhaps this suggests that imperialism always appears reasonable from the perspective of the imperialist. The point of note is that discussions of interdisciplinary research can get hopelessly caught up with precisely what is meant by 'inter' and 'disciplinary' - do these terms denote forms of imperialism, compromise, engagement, development or something else? Are disciplines to be brought together to provoke, to fit seamlessly together or to inspire new ways forward? Is adherence to a discipline unnecessarily conservative? In the rush to proclaim our work as interdisciplinary (perhaps to secure funding) what is placed under threat? It seems to me that inter-, trans-, multi- and post-disciplinary terms risk losing both the history of a discipline (and these histories might provide valuable lessons) and the specific values of disciplines (in terms of both the 'value' of a disciplinary community and as a community with specific 'values' which can be drawn on in moments of engagement). The collection in this sense might be seen as a kind of risk, taking on the burdens of imperialism, disciplines and bland generic-ism.

However, I think this collection suggests a different way forward which eschews those risks and pursues a distinct way of approaching questions regarding the potential utility of organizational ethnography. As I mentioned in the preceding section of this chapter, explorations of interactive social science and the question of utility have suggested that research users rarely pre-exist researchers' attempts to constitute them. That is, researchers have to work hard to identify potentially relevant audiences and then convince audiences they should take part in research or dissemination because researchers have something of value to communicate. We should not assume that this operates in a comfortably generic interdisciplinary fashion. Instead, what the collection and its editors have done is build a 
range of specific insights, approaches, findings and provocations. The collection in this sense does not just build a text, but builds a world of relations into the collection, between researchers, approaches, organizations, provocation and their readers. A version of the world out there (readers, policies, histories) is brought to the research and hopefully proposed relations endure with organizations and readers who might find the content useful. However for these relations to endure, explicit recognition needs to be paid to the characteristics of particular disciplines. For example, while anthropologists might work with conventions which suggest that attempts to demonstrate relevance can be made through drawing on ethnographic depth, those working in management research might instead be used to claims to relevance which draw on multiple case-studies' breadth. Similar differences might be identified between non-academic audiences. The assumption that breadth and depth and any other convention of proving can be comfortably drawn together or even switched in demonstrations of the value of interdisciplinary research, overlooks the values and commitments each discipline would seek to extol - attempts to bring disciplines together need to recognise this tension.

For me, this is where the key strength of this collection emerges. It is not a collection which seeks to merge or combine disciplines. It does not look to smooth out distinctions between approaches. It does not try to account for difference. In this way, the text builds a collective concern by gathering together multiple singularities rather than through mixing multidisciplines into one generic approach. Alongside building a range of insights, approaches, findings and provocations, the collection involves a method (ethnography) and a topic (maternal and child health) which is simultaneously singular within chapters, but also importantly, multiple across chapters. For me it is this kind of multiplicity which maintains disciplines while also offering disjuncture between approaches this collective concern to endure.

\section{References}

Atkinson, P. (1992) Understanding ethnographic texts, London: Sage

Atkinson, P. (1990) The Ethnographic Imagination: Textual Constructions of Reality (Routledge, London)

Baba, M. (2005) To the End of Theory-Practice 'Apartheid': Encountering the world (EPIC Conference proceedings: 205-17, 13-15 November)

Baba, M. (1986) 'Business and Industrial Anthropology: An overview' NAPA bulletin, American Anthropological Association

Bate, S. (1997) 'Whatever happened to organizational anthropology? A review of the field of organizational ethnography and anthropological studies’ Human Relations 50(9): 1147-76

Becker, H. (1973) Outsiders: Studies in the Sociology of Deviance (Free Press, London)

Bergman, M. (2003) 'The broad and narrow in ethnography on organizations' Forum Qualitative Social Research Vol. 4(1): http://www.qualitative-research.net/fqs-texte/1-03/1-03tagung-bergman-e.pdf

Burack, T. (2002) Book Review of 'Turning Words, Spinning Worlds by M. Rosen’ JBTC, April: 220-222

Burgess, R. (1984) In the Field: An Introduction to Field Research (Routledge, London) 
Caswill, P. and Shove, E. (eds) (2000) "Interactive social science”, special issue of Science and Public Policy 27 (3)

Cohen, S. (1972) Folk Devils And Moral Panics (MacGibbon \& Kee, London).

Cussins, C. (1995) "Ontological Choreography: Agency Through Objectification in Infertility Clinics," Social Studies of Science, (26) pp. 575-610

Czarniawska-Joerges, B. (1992) Exploring Complex Organizations. A Cultural Perspective (Sage, London)

Darrah, C. (1996) Learning and Work: An Exploration in Industrial Ethnography (Garland Science, USA)

de Waal Malefyt, T. and Moeran, B. (2003) (eds) Advertising Cultures, Oxford: Berg

Dey, C.R. (2002) "Methodological Issues: The Use of Critical Ethnography as an Active Research

Methodology", Accounting, Auditing and Accountability Journal, Vol. 15(1): 106-21

Du Gay, P. and Salaman, G. (1992) The cult(ure) of the customer. Journal of Management Studies 29(5):61533.

Ellen, R. (ed.) (1984) Ethnographic Research: A Guide to General Conduct (Academic Press, London)

Evans Pritchard, E. (1940) The Nuer: A description of the modes of livelihood and political institutions of a Nilotic people (Clarendon Press, Oxford).

Fetterman, D. (1989) Ethnography Step by Step (Sage, London)

Fielding, N. (2001) 'Ethnography' in Gilbert, N. (ed) 'Researching Social Life' (2 ${ }^{\text {nd }}$ Edition, Sage, London) 147-63

Geertz, C. (1973) The Interpretation of Cultures (Basic Books, New York).

Gibbons, M. (2000) Mode 2 society and the emergence of context sensitive science. Science and Public Policy, Journal of the International Science Policy Foundation, Special Issue on Interactive Social Science 27(3): 15963.

Hammersley, M. and Atkinson, P. (1995) Ethnography: Principles in Practice (2nd edition, Routledge, London)

Harrington, B. (2003) 'The Social Psychology of Access in Ethnographic Research' Journal of Contemporary Ethnography, Vol. 32, No. 5, 592-625

Heller, F. (1986) Introduction. In The use and abuse of social science, edited by F. Heller, 1-18 (Sage, London)

Hughes, J. Randall, D. and Shapiro, D. (1992) 'Faltering from ethnography to design,' Proceeds of CSCW Toronto: ACM

Jeffrey, B. and Troman, J. (2004) 'Time for ethnography’ British Educational Research Journal, Vol. 30, No. 4, 535-548

Knorr Cetina, K. (1999) Epistemic Cultures. How the Sciences Make Knowledge. Harvard University Press, London.

Kuper, A. (1983) Anthropology and Anthropologists: The modern British School (Routledge and Kegan Paul, London)

Latour, B. and Woolgar, S. (1979) Laboratory Life - The Construction of Scientific Facts (Princeton University Press, New Jersey).

Law, J. (2004) After Method: Mess in Social Science Research (Routledge, London) 
Malefyt, T. and Moeran, B. (2003) Advertising Cultures (Berg, Oxford)

Malinowski, B. (1929) The Sexual Life of Savages in Western Melanesia (Harcourt Brace and World, New York, USA)

Miller, D. and Slater, D. (2000) The Internet: An ethnographic approach (Berg, Oxford).

Moeran, B. (2005) The Business of Ethnography - Strategic Exchanges, People and Organizations. (Berg, Oxford).

Mol, A. (2002) The Body Multiple: ontology in medical practice. London: Duke University Press.

Neyland, D. (2006) Privacy, Surveillance and Public Trust (Palgrave-Macmillan, London)

Neyland, D. (2008) Organizational Ethnography. Sage, London.

Neyland, D. and Coopmans, C. (2014) Visual Accountability. Sociological Review 62(1): 1-23.

Pigg, S. (2013) On Sitting and Doing: Ethnography as Action in Global Health. Social Science and Medicine, 99: 127-34.

Radcliffe-Brown, A. (1922) The Andaman Islanders: a study in social anthropology (Cambridge University Press, Cambridge).

Rappert, B. (1997) 'Users and social science research: Policy, problems and possibilities' Sociological Research On-Line 2(3): http://www.socresonline.org.uk/socresonline/2/3/10.html

Rosen, M. (2000) Turning Words, Spinning Worlds: Chapters in Organizational Ethnography (Routledge, London)

Schwartzman, H. (1993) Ethnography in Organizations (Sage, London).

Shove, E. and Rip, A. (2000) 'Symbolic users - Users and unicorns: a diagnosis of mythical beasts in interactive science' Science and Public Policy, Journal of the International Science Policy Foundation, Special Issue on Interactive Social Science 27(3):175-82.

Suchman, L. (2000) Anthropology as 'Brand': Reflections on corporate anthropology (American Anthropological Association annual meeting, San Francisco, USA November 15)

Urry, J. (1984) 'A history of field methods' in Ellen, R. (ed) Ethnographic Research: A guide to general conduct (Academic Press, London)

Van Maanen, J. (1979) 'The Fact of Fiction in Organizational Ethnography' Administrative Science Quarterly 24(4): 539-50

Wagner, P. Weiss, C. Wittrock, B. and Wollman, H. (1991) 'The policy orientation: Legitimacy and promise' in: Social sciences and modern states - National experiences and theoretical crossroads, edited by P. Wagner, C. Weiss, B. Wittrock and H. Wollman, 2-27 (Cambridge University Press, Cambridge).

Weiss, C. and Bucuvalas, M. (1980) Social science research and decision making (Columbia University Press, New York, USA)

Whittington, R. (2004) 'Strategy after modernism: recovering practice’ European Management Review Vol 1(1): $62-68$

Whyte, W. (2 $2^{\text {nd }}$ Edition, 1955) Street Corner Society (University of Chicago Press, Chicago, USA)

Woolgar, S. (2000) Social basis of interactive social science. Science and Public Policy, Journal of the International Science Policy Foundation, Special Issue on Interactive Social Science, 27(3):165-73. 
Woolgar, S. (2002a) Virtual Society? - the social science of electronic technologies,

ESRC End of Programme Report, University of Oxford

Woolgar, S. (2002b) 'The boundaries of accountability: a technographic approach' Paper presented to EASST Conference, University of York, 2nd August

Woolgar, S. (ed) (2002c) Virtual Society? - technology, cyberbole, reality, Oxford : Oxford University Press 